\title{
Science and policy characteristics of the Paris Agreement temperature goal
}

\author{
Carl-Friedrich Schleussner ${ }^{1,2 \star}$, Joeri Rogelj3,4, Michiel Schaeffer ${ }^{1,5}$, Tabea Lissner ${ }^{1,2}$, Rachel Licker ${ }^{6}$, \\ Erich M. Fischer ${ }^{4}$, Reto Knutti ${ }^{4}$, Anders Levermann ${ }^{2,7,8}$, Katja Frieler $^{2}$ and William Hare ${ }^{1,2}$
}

The Paris Agreement sets a long-term temperature goal of holding the global average temperature increase to well below $2{ }^{\circ} \mathrm{C}$, and pursuing efforts to limit this to $1.5^{\circ} \mathrm{C}$ above pre-industrial levels. Here, we present an overview of science and policy aspects related to this goal and analyse the implications for mitigation pathways. We show examples of discernible differences in impacts between $1.5^{\circ} \mathrm{C}$ and $2{ }^{\circ} \mathrm{C}$ warming. At the same time, most available low emission scenarios at least temporarily exceed the $1.5^{\circ} \mathrm{C}$ limit before 2100 . The legacy of temperature overshoots and the feasibility of limiting warming to $1.5^{\circ} \mathrm{C}$, or below, thus become central elements of a post-Paris science agenda. The near-term mitigation targets set by countries for the 2020-2030 period are insufficient to secure the achievement of the temperature goal. An increase in mitigation ambition for this period will determine the Agreement's effectiveness in achieving its temperature goal.

T he ultimate objective of the United Nations Framework Convention on Climate Change (UNFCCC) is to "prevent dangerous anthropogenic interference with the climate

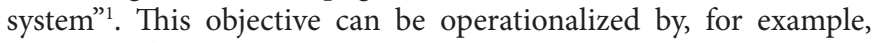
expressing 'dangerous anthropogenic interference' (DAI) in terms of a global long-term temperature goal (LTTG). However, this translation depends on world-views; on political, legal and other value judgements; and on continuous evaluation ${ }^{2}$. Scientific assessments, such as those by the IPCC, are not in the position to recommend specific levels of warming or greenhouse gas (GHG) concentrations. Nevertheless, they provide essential information for science-based political decisions by outlining the impacts, risks and vulnerabilities, as well as technological, economic and feasibility assessments associated with different goals ${ }^{2}$.

Here we reflect on science and policy aspects relating to the temperature and mitigation goals of the Paris Agreement ${ }^{3}$. First, we give a short history of the emergence of $1.5^{\circ} \mathrm{C}$ and $2{ }^{\circ} \mathrm{C}$ as limits in the policy debate followed by an overview of the current understanding of the differences in impact indicators between these two warming levels. We then examine the mitigation architecture of the Paris Agreement and how it is designed to progressively increase mitigation ambition to meet its global LTTG. In this context, we assess characteristics of emission pathways from the scientific literature. Finally, we outline implications for technological requirements and near-term action, and discuss elements of a post-Paris science agenda.

\section{A short history of temperature goals}

The adoption of the LTTG in the Paris Agreement stems from a long-standing climate policy debate. In 1996, the EU Environment Council was first to identify a global mean temperature (GMT) increase of $2{ }^{\circ} \mathrm{C}$ above pre-industrial levels as a limit not to be exceeded, based on the IPCC's Second Assessment Report ${ }^{4}$. This was subsequently confirmed by EU heads of government in 2005 and $2007^{4}$, mainly informed by the IPCC's Third Assessment
Report (TAR) ${ }^{5}$ in 2001. Eventually, this 'not exceed' limit was taken up by the G8 in $2009^{4}$.

The gradual adoption of specific warming limits by political bodies can be linked to the evolution of the underlying scientific basis. Although not comprehensive, progress in the understanding of climate impacts and their relation to GMT increase might be best illustrated by the temporal evolution of the IPCC's 'reasons for concern' (RFCs), a framework for aggregating impacts, risks and vulnerabilities that was first developed in 2001 for the TAR ${ }^{5}$. With scientific insights steadily progressing, assessments based on the IPCC's Fourth Assessment Report (AR4) ${ }^{6}$ and Fifth Assessment Report (AR5) ${ }^{7}$ have identified higher risks for all RFCs at lower temperature levels.

Informed by the conclusions of the IPCC AR4 ${ }^{8}$, approximately 100 countries at the UNFCCC Copenhagen Conference (COP15) in 2009 were calling for warming to be limited to below $1.5^{\circ} \mathrm{C}$ relative to pre-industrial levels $s^{4,9}$. Although COP15 itself was widely regarded as a failure, two politically durable outcomes from the Copenhagen Accord ${ }^{10}$ have ultimately translated into the Paris Agreement: first was the emergence of a long-term goal agreed at head-of-government level, expressed then as an aim to hold the increase in warming below $2{ }^{\circ} \mathrm{C}$, combined with a recognition that deep cuts in global emissions are required 'according to science.' Second, and directly linked, was the agreement to review the 'hold below $2{ }^{\circ} \mathrm{C}$ ' long-term goal with a view to strengthening it, addressing the $1.5^{\circ} \mathrm{C}$ limit called for by vulnerable countries.

The hold below $2{ }^{\circ} \mathrm{C}$ goal was formally agreed upon in 2010 at the COP16 in Cancun and tied to a review of the adequacy of this limit with a view to examining $1.5^{\circ} \mathrm{C}$ as an alternative ${ }^{11}$. Although this led to little or no reaction in scientific circles, a science-based review process under the UNFCCC was established: the structured expert dialogue (SED). Based principally on IPCC AR5 science, the SED concluded ${ }^{12}$ that the "concept, in which up to $2^{\circ} \mathrm{C}$ of warming is considered safe, is inadequate" and that "limiting global warming to below $1.5^{\circ} \mathrm{C}$ would come with several advantages". At the same time, substantial research gaps with regard to $1.5^{\circ} \mathrm{C}$ science were identified ${ }^{12}$.

${ }^{1}$ Climate Analytics, 10969 Berlin, Germany. ${ }^{2}$ Potsdam Institute for Climate Impact Research, 14473 Potsdam, Germany. ${ }^{3}$ Energy Program, International Institute for Applied Systems Analysis, 2361 Laxenburg, Austria. ${ }^{4}$ Institute for Atmospheric and Climate Science, ETH Zurich, 8092 Zürich, Switzerland. ${ }^{5}$ Environmental Systems Analysis Group, Wageningen University and Research Centre, 6708 PB Wageningen, the Netherlands. ${ }^{6}$ Woodrow Wilson School of Public and International Affairs, Princeton University, Princeton, New Jersey 08544, USA. ${ }^{7}$ Institute of Physics and Astronomy, University of Potsdam, 14476 Potsdam, Germany. ${ }^{8}$ Lamont-Doherty Earth Observatory, Columbia University, New York 10964-1000, USA. *e-mail: carl.schleussner@climateanalytics.org 
a

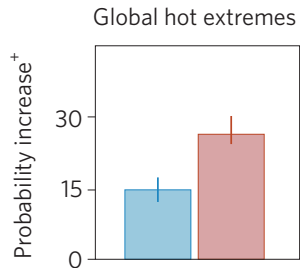

b

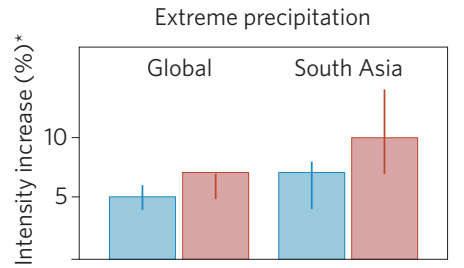

c Mediterranean water availability

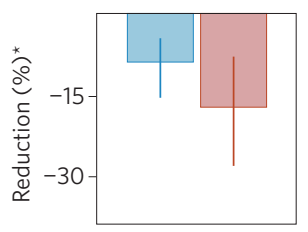

d

Coral reef degradation

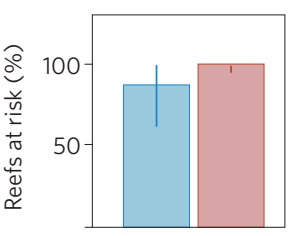

e

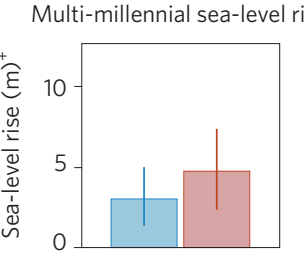

$\mathbf{f}$

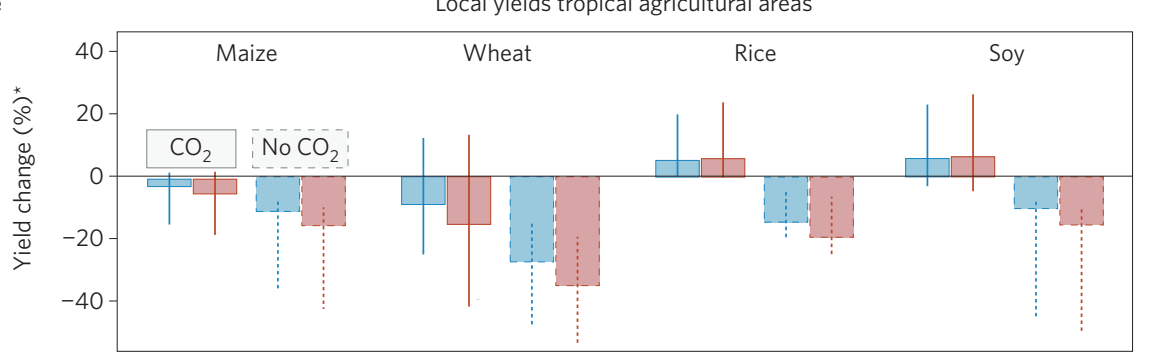

Legend:

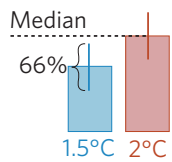

Impact indicator reference period: $\left({ }^{+}\right)$Pre-industrial (*) 1986-2005

Figure 1 | Projected impacts at $1.5^{\circ} \mathrm{C}$ and $2^{\circ} \mathrm{C} \mathrm{GMT}$ increase above pre-industrial levels for a selection of indicators and regions. a, Increase in global occurrence probability of pre-industrial 1-in-a-1000 day extreme temperature events ${ }^{17}$. $\mathbf{b}$, Increase in extreme precipitation intensity (RX5Day) for the global land area below $66^{\circ} \mathrm{N} / \mathrm{S}$ and South Asia ${ }^{21}$. c, Reduction in annual water availability in the Mediterranean ${ }^{21}$. d, Share of global tropical coral reefs at risk of long-term degradation ${ }^{37}$. e, Global sea-level rise commitment for persistent warming of $1.5^{\circ} \mathrm{C}$ and $2^{\circ} \mathrm{C}$ over 2000 years ${ }^{44}$. $\mathbf{f}$, Changes in local crop yields for present-day tropical agricultural areas ${ }^{21}$ (below $30^{\circ} \mathrm{N} / \mathrm{S}$, model dependent implementation of present day management ${ }^{24}$ ). Dashed boxes: no increase in $\mathrm{CO}_{2}$ fertilization $\left(\mathrm{No} \mathrm{CO}_{2}\right.$ ). Panels $\mathbf{b}, \mathbf{c}$ and $\mathbf{f}$ display median changes that are exceeded for over $50 \%$ of the respective land areas.

\section{Climate impacts at $1.5^{\circ} \mathrm{C}$ and $2{ }^{\circ} \mathrm{C}$ warming}

Recent scientific literature allows for an assessment of differences in climate projections and impacts at $1.5^{\circ} \mathrm{C}$ and $2{ }^{\circ} \mathrm{C}$ that goes beyond AR5. We do not aim to provide a full review, but use a regionaland impact-specific approach to highlight differences for selected impacts $^{13}$ (Fig. 1). All impacts are assessed at a GMT increase of $1.5^{\circ} \mathrm{C}$ and $2{ }^{\circ} \mathrm{C}$ above pre-industrial levels. For impact indicators that are expressed relative to the 1986-2005 period (with a GMT increase of about $0.6^{\circ} \mathrm{C}$ above the $1850-1900$ average ${ }^{14}$, our approximation for pre-industrial levels), the results thus relate to a warming of $0.9^{\circ} \mathrm{C}$ or $1.4^{\circ} \mathrm{C}$ above the recent past.

The occurrence of hot temperature-related extremes has increased robustly over the historical period ${ }^{15,16}$. As temperatures rise, the frequency of hot extremes above a fixed threshold increases non-linearly. In a $2{ }^{\circ} \mathrm{C}$ warmer world, the global occurrence probability of a pre-industrial 1-in-a-1000 day extreme temperature event is projected to be about double compared to $1.5^{\circ} \mathrm{C}$ (ref. 17; Fig. 1a). This is about 27 times higher compared to pre-industrial levels and more than five times higher than today.

Patterns of precipitation-related changes are considerably more uncertain $^{18}$. Nevertheless, the increase of extreme precipitation events due to anthropogenic warming is evident from the observational record ${ }^{19,20}$ and the intensity of heavy precipitation events is projected to robustly increase globally between a $1.5^{\circ} \mathrm{C}$ and $2{ }^{\circ} \mathrm{C}$ warming ${ }^{21}$. These changes are particularly pronounced in specific regions such as the high latitudes and South Asia (Fig. 1b). Equally, the global occurrence probability of a 1-in-a-1000 day extreme precipitation event is estimated to increase by about $45 \%$ (full model uncertainty range: $28-70 \%$ ) at $1.5{ }^{\circ} \mathrm{C}$ compared to pre-industrial levels and by $65 \%(41-100 \%)$ at $2{ }^{\circ} \mathrm{C}$ (ref. 17). Changes in the water cycle may be experienced by half of the world's population at a warming of $2{ }^{\circ} \mathrm{C}$ (ref. 22).

Contrary to an almost global increase in heavy precipitation events, only about $25 \%$ of the global land area is projected to experience substantial changes in dry spell length at $2{ }^{\circ} \mathrm{C}$ warming ${ }^{21}$. Projected changes are most pronounced for subtropical regions, in particular the Mediterranean. Patterns of change in water availability emerge similar to changes in water-cycle extremes ${ }^{23}$.
Although global changes are not significant, an increase in total water availability is projected for high-latitude regions, as well as the South Asian monsoon regions for both a $1.5^{\circ} \mathrm{C}$ and $2{ }^{\circ} \mathrm{C}$ warming $^{21}$. At the same time, water availability is projected to decrease in subtropical regions, and most prominently in the Mediterranean, where the projected median reduction of at least $9 \%$ at $1.5{ }^{\circ} \mathrm{C}$ over $50 \%$ of the region's land area nearly doubles to at least $17 \%$ at $2{ }^{\circ} \mathrm{C}$ (ref. 21; Fig. 1c).

Crop yield projections are subject to considerable uncertainty arising from both uncertainty in projections of climate as well as crop models ${ }^{24}$. In addition, many factors affecting crop yield projections - such as elevated $\mathrm{CO}_{2}$ and ozone concentrations ${ }^{25,26}$ as well as management options ${ }^{27,28}$, nitrogen limitations ${ }^{29}$ and the impact of heat extremes ${ }^{30}$ - are not well-constrained and are represented very differently across agricultural model ${ }^{31}$. Observational evidence indicates that substantial impacts of extremes on crop yields are already evident in the second half of the twentieth century ${ }^{32}$.

These substantial uncertainties, particularly regarding the efficiency of the $\mathrm{CO}_{2}$ fertilization effect, render a robust differentiation between climate impacts on crop yields between $1.5^{\circ} \mathrm{C}$ and $2{ }^{\circ} \mathrm{C}$ difficult. However, using multi-model intercomparison data, some general patterns can be identified for the four most common global crop types: maize, wheat, rice and soy (Fig. 1f). Although high latitudes may gain, local wheat and maize crop yield reductions are projected over the tropical land area $\left(30^{\circ} \mathrm{S}-30^{\circ} \mathrm{N}\right)$ at $1.5^{\circ} \mathrm{C}$ warming, with more significant reductions projected at $2{ }^{\circ} \mathrm{C}$ (ref. 21). The vulnerability of wheat and maize production in tropical regions is also evident from a meta-analysis of crop yield projections ${ }^{27}$. Using multi-model ensemble projections that resemble observed yields, it is estimated that global wheat production will decrease by about $6 \%$ per ${ }^{\circ} \mathrm{C}$ of warming ${ }^{33}$. At $1.5{ }^{\circ} \mathrm{C}$ and $2{ }^{\circ} \mathrm{C}$ warming, local rice and soy yields are projected to increase in the tropics compared to present-day yields, as the positive effect of $\mathrm{CO}_{2}$-fertilization counterbalances the detrimental impacts of climate change in the model projections. However, additional gains for warming above $1.5^{\circ} \mathrm{C}$ are limited (compare with Fig. 1f), and reductions are evident for all crop types for projections that exclude the effects of $\mathrm{CO}_{2}$ fertilization ${ }^{21,24}$. 
Table 1 | Paris Agreement elements.

\section{Element}

The long-term

temperature goal

(Article 2) and

related science

(10/CP.21)

\section{Paris Agreement and/or COP21 Decision language}

Article 2.1(a): "Holding the increase in the global average temperature to well below $2^{\circ} \mathrm{C}$ above pre-industrial levels and pursuing efforts to limit the temperature increase to $1.5^{\circ} \mathrm{C}$ above pre-industrial levels, recognizing that this would significantly reduce the risks and impacts of climate change."

Paragraph 8, 10/CP.21: “Encourages the scientific community to address information and research gaps ... including scenarios that limit warming to below $1.5^{\circ} \mathrm{C}$ relative to pre-industrial levels by 2100 and the range of impacts at the regional and local scales associated with those scenarios".

The long-term global mitigation goals (Article 4.1)

The NDC-update cycle*

Global stocktake this Agreement shall periodically ... assess the collective progres towards achieving the purpose of this Agreement and its longterm goals (the 'global stocktake') ... in the light of ... the best available science."

Article 14.2: "The $[C O P]$... serving as the meeting of the Parties to this Agreement shall undertake its first global stocktake in 2023 and every five years thereafter."

Scientific information for the global stocktake

Paragraphs 99, 100 of Decision 1/CP.21: Identify sources of input for the global stocktake and advice on how the IPCC can inform subsequent global stocktakes.

\section{Interpretation and implications}

This identifies $1.5^{\circ} \mathrm{C}$ as the limit within the LTTG. The expression 'holding ... well below $2^{\circ} \mathrm{C}^{\prime}$ is a strengthening of previous language and signals an increase in both the margin and likelihood by which warming is to be kept below $2^{\circ} \mathrm{C}$ compared to holding below $2^{\circ} \mathrm{C}$ (ref. 11). The probabilities of meeting this limit have substantial implications for mitigation pathways under Article 4.1.

The lowest currently available emission pathways tend to exceed $1.5^{\circ} \mathrm{C}$ during the twenty-first century before reaching this limit, or lower, by 2100. Whether (and under what conditions) warming can be held below $1.5^{\circ} \mathrm{C}$ during the twenty-first century is one of the major research questions arising from Paris.

Achieving a balance between anthropogenic emissions by sources and anthropogenic removals by sinks is equivalent to 'zero global $\mathrm{GHG}$ emissions'. The timing of global peaking in emissions and of zero emissions, as well as the rate of global emission reductions should be consistent with the best available science on technologically and economically feasible pathways. Scientific assessments on progress towards the long term mitigation goals will be part of the 2018 facilitative dialogue and the subsequent global stocktake processes.

The NDCs are at the heart of the Paris Agreement. Communications of new NDCs every five years are required to represent a progression in terms of mitigation ambition beyond the previous NDCs.

Starting in 2018 with a facilitative dialogue, and continuing with fiveyearly global stocktakes from 2023 , the global stocktake process should regularly provide a science based aggregate assessment of Parties contributions and how these relate to global emission pathways consistent with the LTTG and the long-term goals in Article 4.1. The link between the NDC cycle and the stocktake processes is aimed at understanding the necessary increase in global mitigation ambition for it to become consistent with the long-term global goals based on the best available science.

For the first global stocktake in 2023, paragraph 100 of decision 1/ CP. 21 requests advice from a UNFCCC Subsidiary Body (SBSTA) on how future IPCC assessments can inform the global stocktake. There is an expectation that the IPCC will adjust the timing of its Sixth Assessment Report to input into this.

The role of science and in particular the IPCC to inform the first stocktake process (facilitative dialogue in 2018) is laid out in COP21 Decisions. Paragraph 21 of Decision 1/CP.21 invites the IPCC to prepare by 2018 a special report on $1.5^{\circ} \mathrm{C}$, including on $1.5^{\circ} \mathrm{C}$ compatible emission pathways. Paragraph 17 then explicitly calls for information on the 2025 and $2030 \mathrm{GHG}$ emission levels implied by $1.5^{\circ} \mathrm{C}$ compatible pathways to be provided in this report as guidance for much greater emission reduction efforts to be included in NDCs. The ambition mechanism links the NDC-cycle, the global stocktake, and focussed scientific assessments and information. This is essential to provide the scientific basis and advice on what is needed to bridge the gap between nationally determined near-term ambition reflected in NDCs and the collectively expressed long-term goals in the Paris Agreement. Thereby, it is the functionality of this mechanism that will ultimately determine the Paris Agreement's success.

Elements of the Paris Agreement ${ }^{3}$ and its enabling decisions relating to the long-term temperature goal and mitigation architecture (1/CP.21), and related requests to the scientific community (10/CP.21),

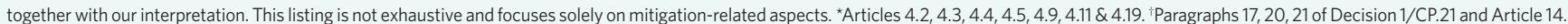
Paragraphs 99,100 of Decision 1/CP.21. 
Also relevant for global food security, ocean ecosystems appear to be particularly vulnerable to anthropogenic GHG emissions due to warming, deoxygenation and ocean acidification ${ }^{34}$. As a result, several key risks for oceanic ecosystems are assessed as severe and widespread due to climate change at warming levels below $1.5^{\circ} \mathrm{C}$ (ref. 35). In particular, global coral reef systems are projected to be threatened by both ocean acidification and thermal stress ${ }^{36,37}$. Projections indicate that nearly all global warm-water coral reef systems will be at risk of long-term degradation at $2{ }^{\circ} \mathrm{C}$ due to temperature-induced bleaching, unless very optimistic scenarios of coral reef adaptation are assumed ${ }^{37}$. Limiting warming to $1.5^{\circ} \mathrm{C}$ reduces the fraction of ocean grid cells with reefs under risk of long-term degradation based on the frequency of bleaching events (Fig. 1d). Similarly, Arctic ecosystems and traditional livelihoods are under substantial pressure as sea-ice vanishes - only a warming of well below $2{ }^{\circ} \mathrm{C}$ may ensure that significant areas of end-of-summer sea-ice remain in the $\mathrm{Arctic}^{38}$. A recent extrapolation of observed sensitivities of nations' economic growth to temperature fluctuation indicates substantial negative effects of climate change on the global economy (ref. 39). The study identifies differences in impacts between $1.5^{\circ} \mathrm{C}$ and $2{ }^{\circ} \mathrm{C}$ on economic production globally, with tropical countries affected most ${ }^{39}$.

Many impacts of climate change, in particular those related to large-scale systems such as ice-sheets and the global oceans, will, even under $1.5{ }^{\circ} \mathrm{C}$ scenarios, not materialize fully until 2100 , but rather over centuries and millennia. Prominent examples include ocean acidification ${ }^{40}$, glacier and ice-sheet melting, sea-level rise $\mathrm{e}^{41,42}$ and loss of permafrost ${ }^{43}$. Model projections, as well as evidence from the palaeo-record, indicate multi-millennial global sea-level rise of several meters per degree of warming, with contributions from the Greenland and partly disintegrated West-Antarctic ice-sheets ${ }^{44,45}$.

The presented collection of differences in impact indicators points towards hot spots of change between $1.5^{\circ} \mathrm{C}$ and $2{ }^{\circ} \mathrm{C}$, particularly in tropical regions. These findings tend to support the earlier assessments by vulnerable countries that $1.5^{\circ} \mathrm{C}$ is a less risky limit than $2{ }^{\circ} \mathrm{C}$ (ref. 9). The following section will examine the mitigation components included in the Paris Agreement and their implications for reaching the LTTG.

\section{The Paris mitigation architecture}

An interlocking set of articles of the Paris Agreement provides the legally binding mitigation ambition architecture of the Agreement ${ }^{46}$. This includes the LTTG in Article 2.1(a), the linked long-term mitigation goals expressed in Article 4.1, and obligations on Parties to progressively increase their mitigation ambition to collectively achieve these goals. Such an increase over time should be realized through successive five-yearly nationally determined contributions (NDCs), which are progressively more ambitious and informed by science assessments. Table 1 outlines key elements of this legally binding mitigation ambition architecture and our respective interpretation.

The LTTG in Article 2.1(a) is operationalized by means of the long-term global mitigation goals in Article 4.1. This includes a peaking of global emissions as soon as possible, with rapid reductions thereafter in accordance with the best available science so as to achieve "a balance between anthropogenic emissions by sources and removals by sinks of greenhouse gases in the second half of this century" ${ }^{3}$. Details of these emission goals are to be determined consistent with the LTTG. The term balance here essentially means that globally aggregated anthropogenic GHG emissions are required to reach zero.

The ambition level of each individual Party, as expressed in each successive NDC, is required to "represent a progression beyond the Party's then current nationally determined contribution" (Article 4.3) ${ }^{3}$. This is part of the ambition mechanism under the Paris Agreement that additionally includes a five-yearly 'global stocktake' of the globally aggregated effects of countries' actions and ambitions with regard to the purpose of the Paris Agreement and its long-term goals. The first stocktake is to be held in 2023 and is a crucial milestone for the Agreement's effectiveness.

Agreed as part of the enabling COP decisions to commence the implementation of the Paris Agreement, a 'facilitative dialogue' will be held in 2018. It is mandated to assess how the global aggregate effect of Parties' commitments (NDCs) and actions are tracking with respect to the long-term global mitigation goals, and to inform the preparation and updating of NDCs for 2025 and 2030. The IPCC was invited (and has since agreed ${ }^{47}$ ) to prepare a Special Report on $1.5^{\circ} \mathrm{C}$ by 2018 , specifically including an assessment of this issue, as well as on the impacts of warming of $1.5^{\circ} \mathrm{C}$.

The content and timing of the facilitative dialogue and the IPCC Special Report on $1.5^{\circ} \mathrm{C}$ will be critical in the context of the request for Parties to the Paris Agreement to communicate or update their NDCs by 2020 so as to increase the level of ambition, both individually and in aggregate terms. The results of this process may well be the first substantive test of the Paris Agreement's effectiveness. Finally, Decision 10/CP.21 encourages the scientific community to conduct research on the gaps identified in the aforementioned SED, including on $1.5{ }^{\circ} \mathrm{C}$ impacts at regional and local scales and scenarios that limit warming below $1.5^{\circ} \mathrm{C}$ above pre-industrial.

\section{Implications for mitigation pathways}

Mitigation pathways in line with different interpretations of the Paris Agreement and the respective solution space have not been systematically explored so far. The following analysis is based upon an ensemble of opportunity of scenarios available in the current literature. These scenarios are derived by integrated assessment models (IAMs) and any conclusions drawn should be mindful of the assumptions underlying these model ${ }^{48}$. Furthermore, the classification of scenarios applied by us should not be seen as an interpretation of the Paris Agreement.

Emissions reduction pathways meeting a specific temperature limit are most commonly interpreted in terms of the probability they imply for staying below such a limit. For example, the hold below $2{ }^{\circ} \mathrm{C}$ limit has often been assessed in the scientific literature, including the IPCC AR5 Synthesis Report ${ }^{49}$, assuming a greater than $66 \%$ or 'likely ${ }^{5}$ probability of holding the increase in GMT below $2{ }^{\circ} \mathrm{C}$ above pre-industrial levels. Such pathways have a median peak twenty-first century warming of, at most, around $1.8^{\circ} \mathrm{C}$ (Fig. 2b). This is also how we will refer to $2{ }^{\circ} \mathrm{C}$ scenarios as a working proxy in the text below. Note that the Paris Agreement's LTTG includes a stronger formulation and refers to holding warming 'well below $2{ }^{\circ} \mathrm{C}^{\prime 3}$. This signals an increase in both the margin and likelihood by which warming is to be kept below $2^{\circ} \mathrm{C}$ (Table 1 ).

Figure $2 \mathrm{a}$ shows the joint probability assessments of emission pathways for holding warming below $2{ }^{\circ} \mathrm{C}$ over the course of the twenty-first century, and to below $1.5^{\circ} \mathrm{C}$ by 2100 based on emission pathways from the IPCC AR5 and a more recent review of $1.5{ }^{\circ} \mathrm{C}$ scenarios ${ }^{51}$. A likely below $2{ }^{\circ} \mathrm{C}$ criterion alone (light-grey shading Fig. 2a) is insufficient to bring warming below $1.5^{\circ} \mathrm{C}$ by 2100 with a probability of at least $50 \%$. However, if the probability of staying below $2{ }^{\circ} \mathrm{C}$ increases to more than $80 \%$ (dark grey shading Fig. 2a), most scenarios assessed would return to below $1.5^{\circ} \mathrm{C}$ with a probability of greater than $50 \%$ before 2100 . Such scenarios have overshoots of, at most, about $0.2^{\circ} \mathrm{C}$ above $1.5^{\circ} \mathrm{C}$ during the twentyfirst century (Fig. 2b) and are at present used as proxies for $1.5^{\circ} \mathrm{C}$ pathways (also in this study). They may, however, not be consistent with legal interpretations and political understandings of the Paris Agreement LTTG by vulnerable countries and others who see this as a not to exceed limit ${ }^{52}$.

Figure $2 \mathrm{~b}$ illustrates important linkages between the LTTG and the operationalization of long-term mitigation goals in Article 4.1. In particular, achieving zero global emissions in the twenty-first century is in itself insufficient to ensure that warming is limited to either 


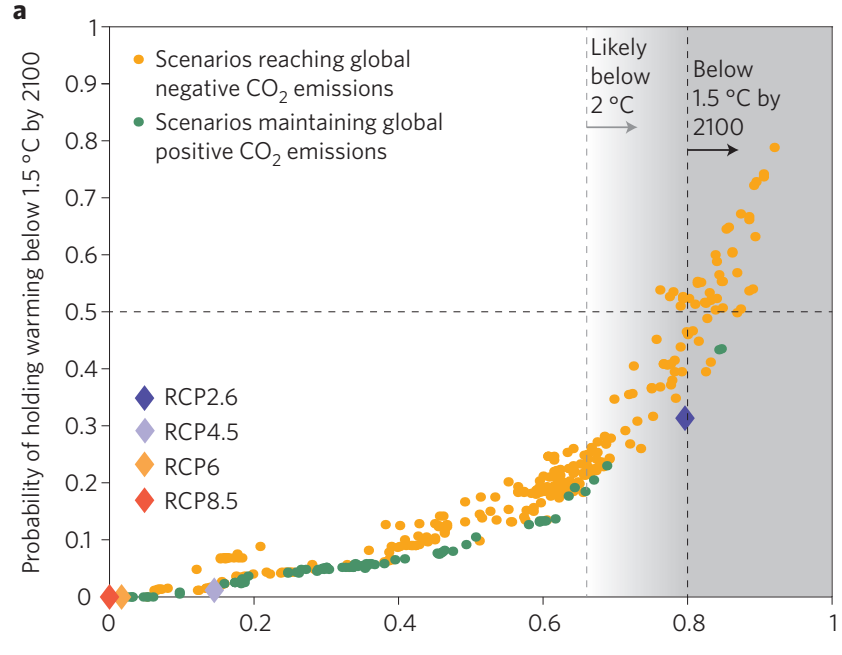

Probability of holding warming below $2{ }^{\circ} \mathrm{C}$ during the twenty-first century b

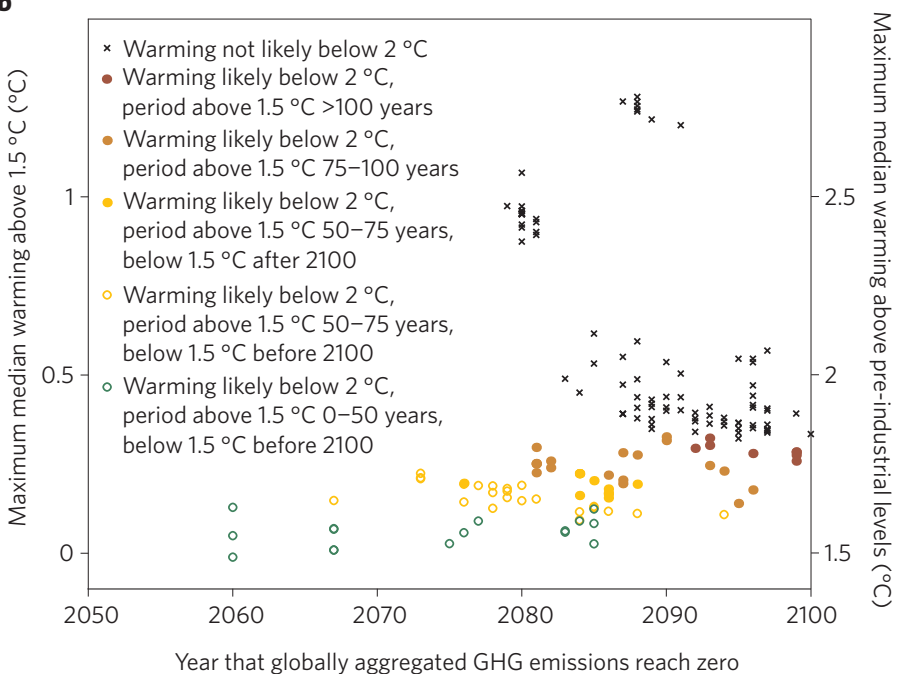

Figure 2 | GMT projections for emission scenarios assessed by the IPCC ${ }^{54}$ and UNEP68. a, Probability of holding warming below $2^{\circ} \mathrm{C}$ during the entire twenty-first century and below $1.5^{\circ} \mathrm{C}$ by 2100 (allowing for overshoot any time before 2100 , if probability by 2100 is at least $50 \%$ ). b, Maximum median warming above $1.5^{\circ} \mathrm{C}$ for scenarios that reach zero globally aggregated GHG emissions in the second half of the twenty-first century (horizontal axis). Empty (filled) circles indicate scenarios for which median warming returns below $1.5^{\circ} \mathrm{C}$ before or by 2100 (after 2100 ). Scenarios have been extended beyond 2100 assuming constant 2100 emission levels. A list of all scenarios included in $\mathbf{b}$ is given in Supplementary Table 2.

$2{ }^{\circ} \mathrm{C}$ or $1.5^{\circ} \mathrm{C}$ (black crosses Fig. 2b, as well as Fig. 3 in ref. 53). The timing and magnitude of peak global emissions is critical, as this plays a major role in determining the cumulative emissions under feasible emissions pathways. A goal of zero emissions on its own can therefore not be seen as a substitute of the cumulative carbon budget approach $^{54,55}$.

Finally, we extend the available scenarios beyond 2100 by assuming constant 2100 emissions $^{56}$ to provide a rough estimate of when median GMT increase in these scenarios would conceivably return to below $1.5^{\circ} \mathrm{C}$. Most $2{ }^{\circ} \mathrm{C}$ scenarios assessed would bring warming to $1.5^{\circ} \mathrm{C}$ (or below) before 2150 . Whether such pathways are actually consistent with the Paris Agreement LTTG is not a scientific but a political question.

\section{Technological implications of zero emissions}

Achieving the Paris Agreement long-term mitigation goals has direct implications for mitigation pathways and technology requirements. The vast majority of $1.5^{\circ} \mathrm{C}$ and $2{ }^{\circ} \mathrm{C}$ scenarios in the current literature peak global emissions around 2020 and reach global negative $\mathrm{CO}_{2}$ emissions in the second half of this century (orange dots in Fig. 2a). In these scenarios, negative $\mathrm{CO}_{2}$ emissions in some sectors and geographical locations are required to compensate for residual GHG emissions (non- $\mathrm{CO}_{2}$ and $\mathrm{CO}_{2}$ ) elsewhere ${ }^{53}$. Such negative $\mathrm{CO}_{2}$ emissions would also allow for a subsequent gradual reversal of warming. However, the feasibility of large-scale deployment of negative emission technologies is not yet established ${ }^{57}$ (see ref. 58 for an extensive review of potentials and limits of negative $\mathrm{CO}_{2}$ emissions technologies).

Several technologies for achieving negative emissions are being discussed $^{58,59}$. Bioenergy (BE) with carbon capture and storage ${ }^{60}$ (CCS) features particularly prominently in present-generation IAMs, due to its estimated cost-competitive potential and its positive energy balance ${ }^{48,58,61}$. In the scenarios underlying Fig. 2, BECCS is deployed in all scenarios that reach negative $\mathrm{CO}_{2}$ emissions, generally alongside considerable uptake through afforestation and reforestation activities. BECCS is deployed at a large scale in both $1.5^{\circ} \mathrm{C}$ and cost-effective likely $2{ }^{\circ} \mathrm{C}$ scenarios by the $2040 \mathrm{~s}^{51}$, with scaling up of the technology typically a few years earlier in $1.5^{\circ} \mathrm{C}$ scenarios ${ }^{51}$. Both scenarios raise questions about the attainable speed of technology deployment, links to potential agricultural efficiency improvements, climate adaptation and increasing food demand ${ }^{62}$.
In the second half of the twenty-first century, BECCS deployment in IAMs reaches levels of bioenergy supply that are close to the limits of sustainable bioenergy supply found in the literature ${ }^{63}$ (Fig. 3). A recent review identified a sustainable technical potential by the year 2050 of up to $100 \mathrm{EJ}$ with high agreement across studies, and between $100 \mathrm{EJ}$ and $300 \mathrm{EJ}$ with moderate agreement ${ }^{63}$. The same review also highlights that deployment beyond $200 \mathrm{EJ}$ could lead to high GHG emissions savings, but warns that technological and governance preconditions need to be met in order to avoid detrimental climate effects, or negative impacts on ecosystems, biodiversity and livelihoods ${ }^{63}$. Regarding the CCS component, total CCS deployment in combination with both bioenergy and fossil-fuel powered systems reaches equal levels of total cumulative $\mathrm{CO}_{2}$ stored by 2100 in the available $1.5^{\circ} \mathrm{C}$ and $2{ }^{\circ} \mathrm{C}$ scenarios (Supplementary Table 1). A somewhat larger fraction of total cumulative CCS is associated with BECCS in $1.5^{\circ} \mathrm{C}$ than in $2{ }^{\circ} \mathrm{C}$ scenarios, consistent with the few years lead-time scaling up BECCS in $1.5^{\circ} \mathrm{C}$ scenarios.

Key differences between $1.5^{\circ} \mathrm{C}$ and $2{ }^{\circ} \mathrm{C}$ scenarios tend to be related to energy efficiency and more rapid near-term reductions ${ }^{51}$. Also in the absence of stringent climate mitigation, the competitive advantages of bioenergy (either in combination or in absence of CCS) compared to fossil fuels can lead to a rapid rise in bioenergy deployment over the coming decades (Fig. 3$)^{48}$. This means that every scenario of a sustainable global future must address the real and genuine concerns related to large-scale deployment of bioenergy, irrespective of the presence of mitigation policies. These concerns include biophysically and societally acceptable limits of land requirements, in addition to the potentially detrimental impacts it might have on food security, and water and nutrient availability ${ }^{58,63}$. However, bioenergy potential does not solely relate to arable crops. A substantial potential for agricultural and forest residues, as well as organic waste exists ${ }^{58,64}$ that might help to reduce land and resource demand ${ }^{65}$ and can create additional revenue streams for farmers ${ }^{63}$. Finally, potential increases in international food prices as a result of large-scale bioenergy deployment must be put into context with increases following climate change impacts that may be substantially larger ${ }^{66}$. Taken together, we find no conclusive evidence that risks to global food security introduced by large-scale bioenergy deployment are increasing in $1.5^{\circ} \mathrm{C}$ scenarios compared to $2{ }^{\circ} \mathrm{C}$ scenarios (Fig. 3). More science is needed to improve our understanding of the climate-food-energy nexus. 
a

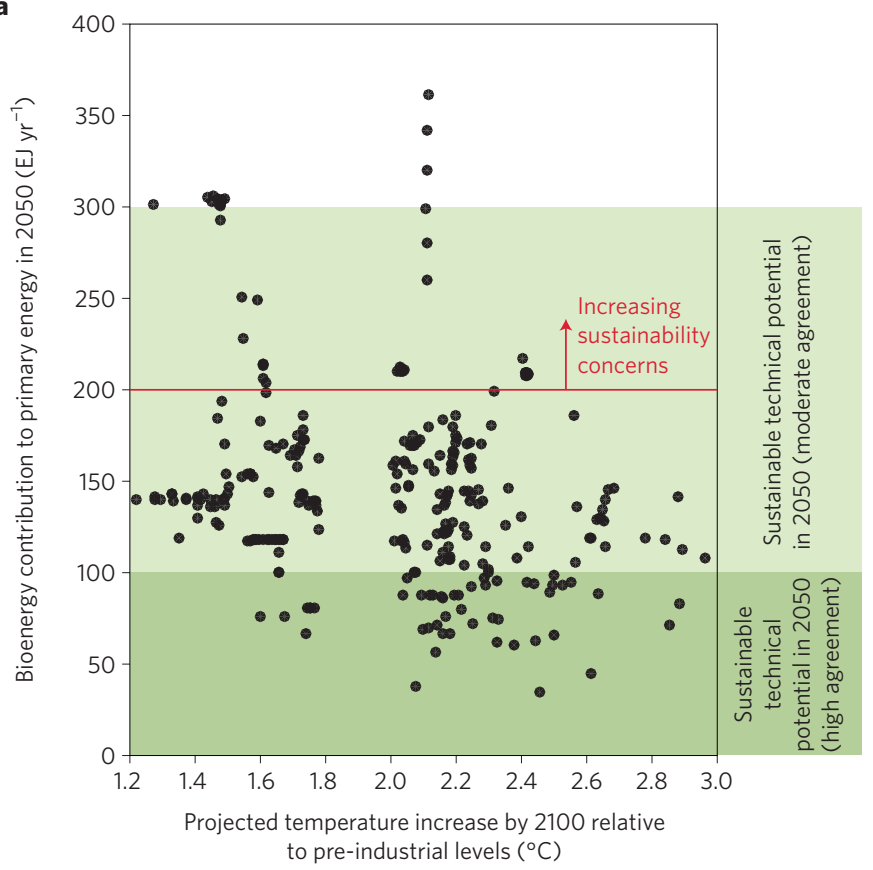

b

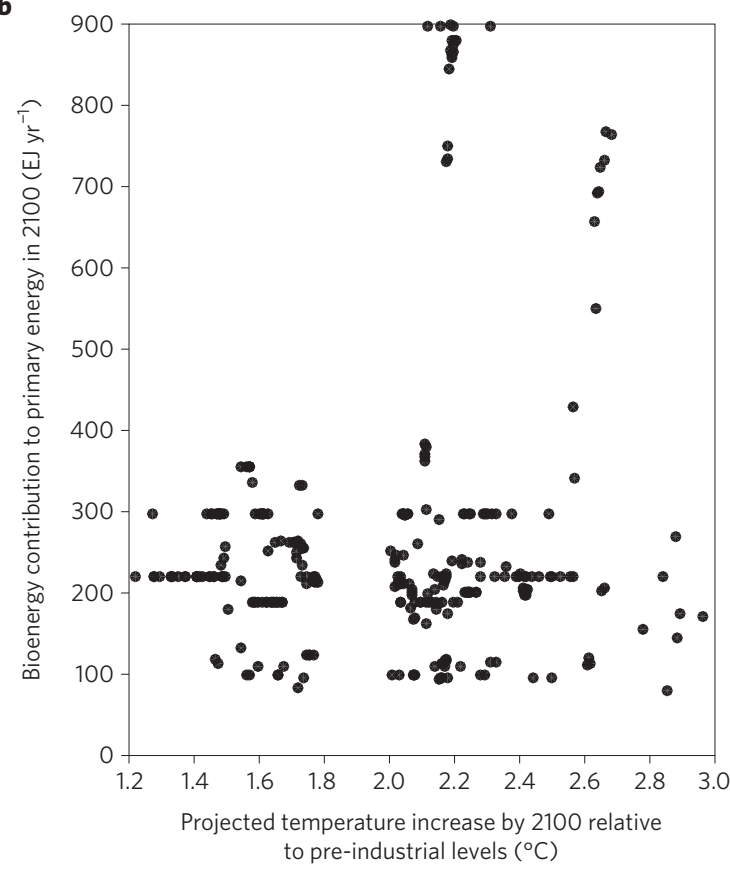

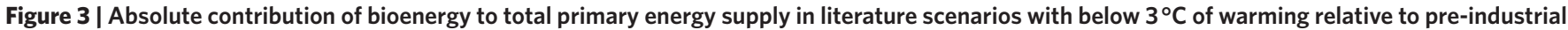
levels by 2100. a, Bioenergy contributions to primary energy in 2050 (black dots represent individual scenarios). Sustainable potentials highlighted in green and light green are based on ref. 63. b. As with $\mathbf{a}$, but for the 2100 primary bioenergy contribution. A list of all scenarios included is given in Supplementary Table 2.

\section{Timing of peak emissions}

Whether limiting warming to below $1.5^{\circ} \mathrm{C}$ with a probability of at least $50 \%$ during the entire twenty-first century is technologically and economically feasible (and if so, under what conditions) is a central question arising from the inclusion of the $1.5^{\circ} \mathrm{C}$ limit in the Paris Agreement. At present, such scenarios have not been explored in the literature on integrated assessment modelling.

When a $2{ }^{\circ} \mathrm{C}$ limit is interpreted loosely (allowing for a temporary overshoot), clear trade-offs between the near and long term have been identified, for example in terms of the timing of peak emissions $s^{48,67}$. This flexibility disappears when aiming for more stringent goals such as a hold below $2{ }^{\circ} \mathrm{C}$ goal with likely or higher probabilities, a $1.5^{\circ} \mathrm{C} \mathrm{limit}{ }^{51}$, or when taking a more precautionary approach assuming limited negative emissions potential ${ }^{58,68,69}$. In addition, any delay in mitigation action implies higher costs ${ }^{51,67,69}$. In 2030, costoptimal emissions pathways limiting temperature increase likely below $2{ }^{\circ} \mathrm{C}$ during the entire twenty-first century, and with greater than $50 \%$ probability of below $1.5^{\circ} \mathrm{C}$ by 2100 , show little difference. Emission trajectories mainly diverge after 2030 (Fig. 4). Such pathways are characterized by a peaking of global GHG emissions by 2020 at the latest and emission levels of approximately 37-39 $\mathrm{GtCO}_{2} \mathrm{e} \mathrm{yr}^{-1}$ in 2030 (refs 68, 70).

Temporal trade-offs are further illustrated by a thought-experiment on pathways limiting warming to below $1.5^{\circ} \mathrm{C}$ in this century shown in Supplementary Fig. 1. Negative $\mathrm{CO}_{2}$ emissions are required in all cases considered. However, peaking global $\mathrm{CO}_{2}$ emissions from industry and energy in 2015, instead of 2030, combined with accelerated decarbonization over the next three decades would avoid the requirement for very large global negative $\mathrm{CO}_{2}$ emissions.

Currently, successful implementation of all the national emission reduction proposals that were submitted to the UNFCCC in the form of intended nationally determined contributions (INDCs) would not result in global GHG emissions peaking before 2030 (orange ranges in Fig. 4a; ref. 71). The 2030 global GHG emission levels implied by the INDCs are far outside the range indicated by cost-effective likely $2{ }^{\circ} \mathrm{C}$ and $1.5^{\circ} \mathrm{C}$ pathways. The situation is even less favourable when looking at policies that are currently in place (purple ranges in Fig. 4a). This underscores the importance of the earlier discussed ambition mechanism (five-yearly NDC cycles combined with a global stocktake, see Table 1) for achieving the required mitigation target improvements.

\section{A post-Paris science agenda}

The use of long-term temperature limits or goals as 'focal points' to guide climate action is primarily rooted in political risk assessments ${ }^{2,72}$. As the underlying science is continuously evolving, so may the outcomes of such science-based political assessments. The inclusion of the $1.5^{\circ} \mathrm{C}$ limit in the Paris Agreement following an extensive science-policy dialogue ${ }^{12}$ and replacing in effect the earlier $2{ }^{\circ} \mathrm{C}$ limit, might be seen as an example of this process ${ }^{73}$.

The Paris Agreement calls for the scientific community to investigate a $1.5^{\circ} \mathrm{C}$ world $\mathrm{d}^{74,75}$. In this context, assessments of climate projections and climate risks need to go beyond global summaries and provide detailed information on regional changes at different levels of warming $13,21,76,77$. This is particularly relevant for impacts that may in some cases exhibit nonlinearities or even show trend reversals with increasing warming ${ }^{78,79}$.

Furthermore, our understanding of the consequences of peak warming and the duration of potential overshoot above $1.5^{\circ} \mathrm{C}$ for associated climate impacts, as well as the longer term (multi-century and millennial) consequences of limiting warming to $1.5^{\circ} \mathrm{C}$, needs to be advanced. This is especially relevant for oceanic changes such as ocean heat uptake and the resulting sea-level rise, but also circulation patterns ${ }^{80,81}$. Similarly, emission-pathway-dependent ocean acidification will leave a century-long legacy in marine environments ${ }^{40}$. Henceforth, the impacts on ocean ecosystems may not be easily reversible, even on centennial timescales.

An assessment of abrupt shifts in the climate system in state-ofthe-art climate models under warming scenarios exceeding $10{ }^{\circ} \mathrm{C}$ and more revealed that about $50 \%$ of all abrupt shifts identified already occur at $2{ }^{\circ} \mathrm{C}$ above pre-industrial levels, compared with about $20 \%$ at $1.5{ }^{\circ} \mathrm{C}$ (ref. 82 ). Whether, and on what time-scales, 


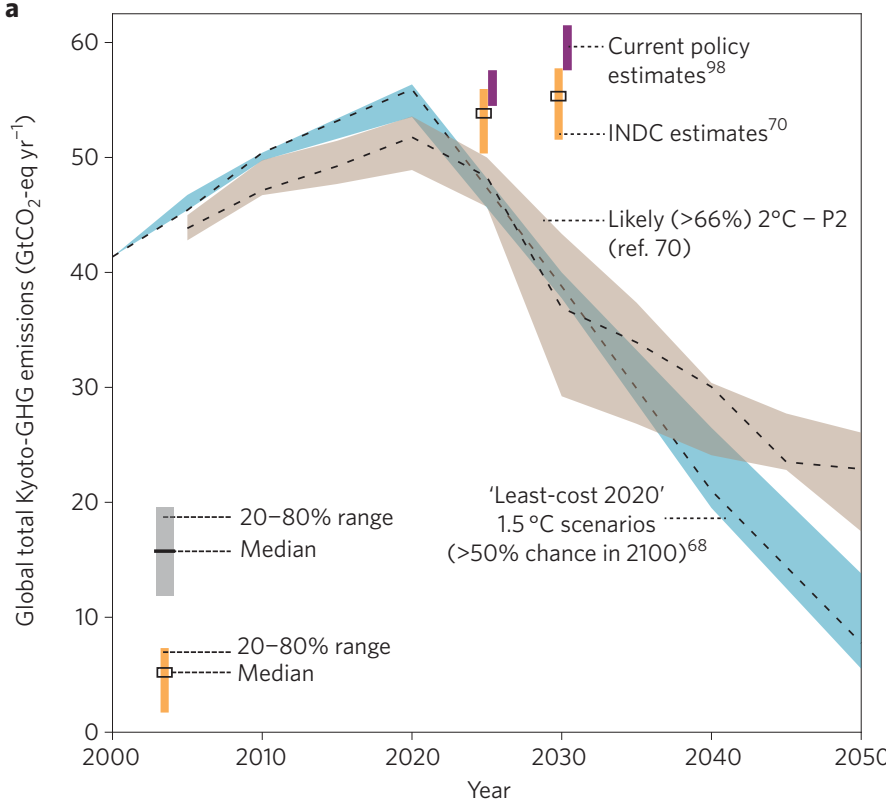

b

Timing of globally aggregated emissions reaching zero

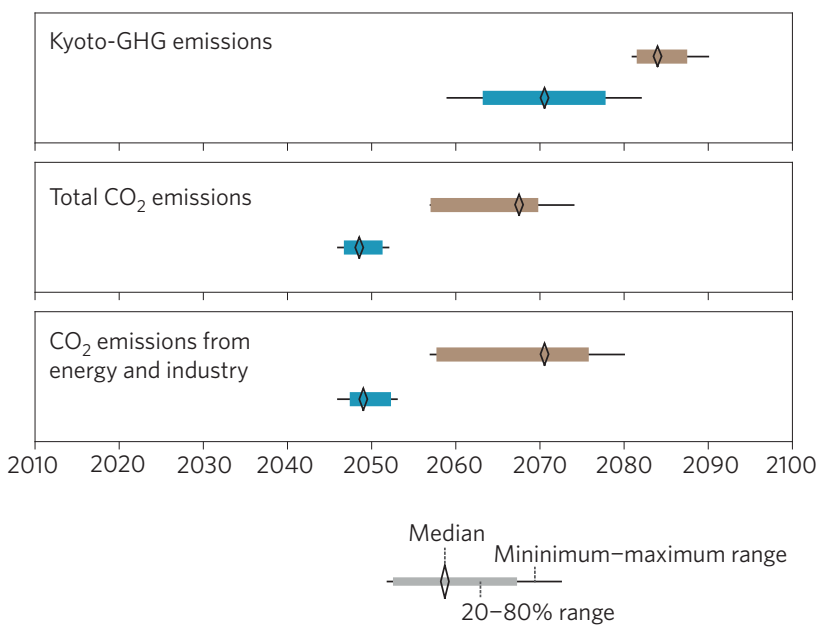

Figure 4 | Characteristics of below $2^{\circ} \mathrm{C}$ and $1.5^{\circ} \mathrm{C}$ pathways. a, Global emissions trajectories for likely below $2^{\circ} \mathrm{C}$ warming scenarios ${ }^{70}$, and scenarios limiting warming to below $1.5^{\circ} \mathrm{C}$ by the end of the century ${ }^{51,68}$. Trajectories are based on integrated scenarios that simulate least-cost pathways for obtaining climate protection from 2020 onward. Current estimates of GHG levels implied by INDCs (orange, data from ref. 70) and current policies (purple, minimum-maximum range from ref. 99) by 2025 and 2030 are indicated. Differences in the historical emissions of both scenario sets are due to differences in the underlying models and arbitrary model sampling. $\mathbf{b}$, Timing of globally aggregated emissions reaching zero for total Kyoto-GHG emissions, total $\mathrm{CO}_{2}$ emissions, and $\mathrm{CO}_{2}$ emissions from energy and industry, respectively. The colours of the ranges correspond to the scenarios shown in panel a. A list of all scenarios included is given in Supplementary Table 2.

such shifts in ocean circulation, sea ice, snow cover, permafrost and terrestrial biosphere are reversible, will be of great relevance when assessing both potential overshoots above $1.5^{\circ} \mathrm{C}$ and the longer-term effects of a below $1.5^{\circ} \mathrm{C}$ limit. Impacts relating to overshoot strength and persistence may also relate to the stability of the Greenland and Antarctic ice sheets. Recent findings from West Antarctica suggest that irreversible marine ice-sheet instability might have already been triggered for several basins ${ }^{83-85}$. Following local disintegration, the entire West-Antarctic ice-sheet might be destabilized by already observed oceanic warming persisting for more than half a century ${ }^{86}$. Other marine basins in East Antarctica are at a similar risk if minor coastal ice volumes are lost ${ }^{87}$. Although currently observed oceanic warming cannot be attributed to climate change with sufficient confidence, twenty-first-century projections indicate substantial circulation changes and subsurface warming around Antarctica ${ }^{88,89}$. To what extent these changes can be related to increases in GMT and whether they can be reversed fast enough to avoid irreversible disintegration of these ice-sheets remains an open question.

An improved understanding of these impact-related questions is crucial to allow for an integrated comparison with the requirements and potential side effects of mitigation pathways. The absence of scenarios that have explicitly looked at limiting warming to below $1.5^{\circ} \mathrm{C}$ during the twenty-first century is an important literature gap. In addition, emission scenarios generally comply with an end-of-century radiative forcing or cumulative emission budget constraint ${ }^{90}$ and are thus not equipped to assess optimal strategies to limit peak warming. Alternative pathways and the potential contribution and timing of non- $\mathrm{CO}_{2}$ GHG mitigation also need to be taken into account. Current activities under the umbrella of the SSP-RCP framework will not remediate these issues, because their present approach is methodologically steered towards assessing end-of-century outcomes ${ }^{90}$.

Whether to limit peak, end-of-century or long-term warming is a political question. Whatever interpretation is made of the
Paris LTTG, it is clear that a large number of developing and highly vulnerable countries view this as a not to exceed $1.5^{\circ} \mathrm{C}$ limit ${ }^{52}$. It is important that the scientific community does not overlook this perspective by excluding certain outcomes by design. Given the policy relevance of these questions and the insights they can provide for required near-term mitigation efforts, the scientific community should aim to fill this gap in time for the upcoming IPCC Special Report on $1.5^{\circ} \mathrm{C}$.

Questions of feasibility, preferences and potential limits of negative emission technologies are of key relevance for mitigation action under the Paris Agreement. To address the full complexity of this issue, an integrated analysis of negative emission technologies should assess optimal technology portfolios, including environmental, social and economic costs, as well as planetary boundaries ${ }^{91}$. Such an approach would benefit from the integration of other sustainable development goals. It could provide guidance on how to minimize or overcome negative side effects of controversial technologies such as large-scale bioenergy deployment ${ }^{63}$.

Negative emission technologies including BECCS, and also alternative technologies such as enhanced weathering or direct air-capture ${ }^{58}$, can be (and often are) included in IAM simulations to reach ambitious mitigation goals. At the same time, knowledge on the technical feasibility of large-scale deployment of these technologies is limited ${ }^{58}$. Only enhancing their political profile - for example, in countries' climate change mitigation strategies and channelling of investments towards these technologies - will allow for the necessary innovation and development beyond their current, preliminary stage $^{92}$. This is a prerequisite for reducing uncertainties about technology feasibility and applicability, and for improving estimates of negative emission potentials.

Finally, the clear inconsistency between the long-term goals in the Paris Agreement and near-term mitigation ambition as expressed in current INDCs needs to be addressed in a solution-oriented manner. Scientific assessments of the potential for increasing ambition 
at the national level ${ }^{93}$ - as well as implications for technology investments - will benefit this process. This is especially the case for currently installed and planned unmitigated coal-fired power generation capacities ${ }^{94}$ that are inconsistent even with a well below $2{ }^{\circ} \mathrm{C}$ limit ${ }^{95}$. Furthermore, assessments of increased near-term ambition will benefit from a comprehensive approach including potential negative side-effects as well as near-term benefits, such as energy security or reduced air pollution ${ }^{96,97}$.

The IPCC Special Report on $1.5^{\circ} \mathrm{C}$ in 2018, and the emerging research it is based upon, are in a very good position to address many of these issues ${ }^{98}$, as they would be timely to inform the 'facilitative dialogue' on the NDCs in the same year. An integrated assessment of what 2025 and 2030 emission levels would entail with regard to long-term warming goals, impacts, potential overshoots, as well as technological needs, is key to providing scientific guidance to this process, thereby facilitating the successful implementation of the Paris Agreement. In the longer term, the IPCC Sixth Assessment Report is being designed to also provide input to the global stock take process in 2023. Its ability to provide policy relevant assessments on the Paris Agreement would be much enhanced by research addressing the issues outlined above.

Received 29 February 2016; accepted 5 July 2016; published online 25 July 2016

\section{References}

1. United Nations Framework Convention on Climate Change (UNFCCC, 1992).

2. Knutti, R., Rogelj, J., Sedláček, J. \& Fischer, E. M. A scientific critique of the two-degree climate change target. Nature Geosci. 9, 13-18 (2015).

3. Adoption of the Paris Agreement FCCC/CP/2015/10/Add.1 (UNFCCC, 2015)

4. Hare, W. L., Cramer, W., Schaeffer, M., Battaglini, A. \& Jaeger, C. C. Climate hotspots: key vulnerable regions, climate change and limits to warming. Reg. Environ. Change 11, 1-13 (2011).

5. IPCC Climate Change 2001: Impacts, Adaptation, and Vulnerability (eds McCarthy, J. J., Canziani, O. F., Leary, N. A., Dokken, D. J. \& White, K. S.) (Cambridge Univ. Press, 2001).

6. Smith, J. B. et al. Assessing dangerous climate change through an update of the intergovernmental panel on climate change (IPCC) "reasons for concern". Proc. Natl Acad. Sci. USA 106, 4133-4137 (2009).

7. Oppenheimer, M. et al. in Climate Change: Impacts, Adaptation, and Vulnerability (eds Field, C. B. et al.) 1039-1099 (IPCC, Cambridge Univ. Press, 2014).

8. IPCC Climate Change 2007: Synthesis Report (eds Pachauri, R. K. \& Reisinger, A.) (Cambridge Univ. Press, 2007).

9. Submissions from Parties FCCC/KP/AWG/2009/MISC.1/Add.1 (UNFCCC, 2009).

10. The Copenhagen Accord FCCC/CP/2009/11/Add.1 (UNFCCC, 2009).

11. The Cancun Agreements FCCC/CP/2010/7/Add.1 (UNFCCC, 2010).

12. Report on the Structured Expert Dialogue on the 2013-2015 Review FCCC/ SB/2015/INF.1 (UNFCCC, 2015).

13. Seneviratne, S. I., Donat, M. G., Pitman, A. J., Knutti, R. \& Wilby, R. L. Allowable $\mathrm{CO}_{2}$ emissions based on regional and impact-related climate targets. Nature 529, 477-483 (2016).

14. IPCC Climate Change 2013: The Physical Science Basis (eds Stocker, T. F. et al.) (Cambridge Univ. Press, 2013).

15. IPCC Managing the Risks of Extreme Events and Disasters to Advance Climate Change Adaptation (eds Field, C. B. et al.) (Cambridge Univ. Press, 2012).

16. Seneviratne, S. I., Donat, M. G., Mueller, B. \& Alexander, L. V. No pause in the increase of hot temperature extremes. Nature Clim. Change 4, 161-163 (2014).

17. Fischer, E. M. \& Knutti, R. Anthropogenic contribution to global occurrence of heavy-precipitation and high-temperature extremes. Nature Clim. Change 5, 560-564 (2015)

18. Greve, P. et al. Global assessment of trends in wetting and drying over land. Nature Geosci. 7, 716-721 (2014).

19. Westra, S., Alexander, L. V. \& Zwiers, F. W. Global increasing trends in annual maximum daily precipitation. J. Clim. 26, 3904-3918 (2013).

20. Lehmann, J., Coumou, D. \& Frieler, K. Increased record-breaking precipitation events under global warming. Climatic Change 132, 501-515 (2015).

21. Schleussner, C.-F. et al. Differential climate impacts for policy relevant limits to global warming: the case of $1.5^{\circ} \mathrm{C}$ and $2{ }^{\circ} \mathrm{C}$. Earth Syst. Dynam. 7, 327-351 (2016)
22. Sedláček, J. \& Knutti, R. Half of the world's population experience robust changes in the water cycle for a $2{ }^{\circ} \mathrm{C}$ warmer world. Environ. Res. Lett. 9, 044008 (2014).

23. Schewe, J. et al. Multimodel assessment of water scarcity under climate change. Proc. Natl Acad. Sci. USA 111, 3245-3250 (2014).

24. Rosenzweig, C. et al. Assessing agricultural risks of climate change in the 21st century in a global gridded crop model intercomparison. Proc. Natl Acad. Sci. USA 111, 3268-3273 (2013).

25. McGrath, J. M. \& Lobell, D. B. Regional disparities in the $\mathrm{CO}_{2}$ fertilization effect and implications for crop yields. Environ. Res. Lett. 8, 014054 (2013).

26. Tai, A. P. K., Martin, M. V. \& Heald, C. L. Threat to future global food security from climate change and ozone air pollution. Nature Clim. Change 4, 817-821 (2014).

27. Challinor, A. J. et al. A meta-analysis of crop yield under climate change and adaptation. Nature Clim. Change 4, 287-291 (2014).

28. Elliott, J. et al. Constraints and potentials of future irrigation water availability on agricultural production under climate change. Proc. Natl Acad. Sci. USA 111, 3239-3244 (2013).

29. Bodirsky, B. L. et al. Reactive nitrogen requirements to feed the world in 2050 and potential to mitigate nitrogen pollution. Nature Commun. 5, 3858 (2014).

30. Deryng, D., Conway, D., Ramankutty, N., Price, J. \& Warren, R. Global crop yield response to extreme heat stress under multiple climate change futures. Environ. Res. Lett. 9, 034011 (2014).

31. Nelson, G. C. et al. Agriculture and climate change in global scenarios: why don't the models agree. Agric. Econ. 45, 85-101 (2014).

32. Lesk, C., Rowhani, P. \& Ramankutty, N. Influence of extreme weather disasters on global crop production. Nature 529, 84-87 (2016).

33. Asseng, S. et al. Rising temperatures reduce global wheat production. Nature Clim. Change 5, 143-147 (2015).

34. Pörtner, H.-O. et al. in Climate Change 2014: Impacts, Adaptation, and Vulnerability (Field, C. B. et al.) Ch. 6 (IPCC, Cambridge Univ. Press, 2014).

35. Gattuso, J.-P. et al. Contrasting futures for ocean and society from different anthropogenic $\mathrm{CO}_{2}$ emissions scenarios. Science 349, aac4722 (2015).

36. Meissner, K. J., Lippmann, T. \& Sen Gupta, A. Large-scale stress factors affecting coral reefs: open ocean sea surface temperature and surface seawater aragonite saturation over the next 400 years. Coral Reefs 31, 309-319 (2012).

37. Frieler, K. et al. Limiting global warming to $2^{\circ} \mathrm{C}$ is unlikely to save most coral reefs. Nature Clim. Change 3, 165-170 (2013).

38. Hezel, P. J., Fichefet, T. \& Massonnet, F. Modeled Arctic sea ice evolution through 2300 in CMIP5 extended RCPs. Cryosphere 8, 1195-1204 (2014).

39. Burke, M., Hsiang, S. M. \& Miguel, E. Global non-linear effect of temperature on economic production. Nature 527, 235-239 (2015).

40. Mathesius, S., Hofmann, M., Caldeira, K. \& Schellnhuber, H. J. Long-term response of oceans to $\mathrm{CO}_{2}$ removal from the atmosphere. Nature Clim. Change 5, 1107-1113 (2015).

41. Schewe, J., Levermann, A. \& Meinshausen, M. Climate change under a scenario near $1.5^{\circ} \mathrm{C}$ of global warming: monsoon intensification, ocean warming and steric sea level rise. Earth Syst. Dynam. 2, 25-35 (2011).

42. Clark, P. U. et al. Consequences of twenty-first-century policy for multi-millennial climate and sea-level change. Nature Clim. Change 6, 360-369 (2016).

43. Schneider von Deimling, T. et al. Estimating the near-surface permafrostcarbon feedback on global warming. Biogeosci. 9, 649-665 (2012).

44. Levermann, A. et al. The multimillennial sea-level commitment of global warming. Proc. Natl Acad. Sci. USA 110, 13745-13750 (2013).

45. Dutton, A. et al. Sea-level rise due to polar ice-sheet mass loss during past warm periods. Science 349, aaa4019 (2015).

46. Mace, M. J. Mitigation commitments under the Paris Agreement and the way forward. Clim. Law 6, 21-39 (2016).

47. Decision IPCC/XLIII-7 (IPCC, 2016).

48. Clarke, L. et al. in Climate Change 2014: Mitigation of Climate Change (Edenhofer, O. et al.) Ch. 6 (IPCC, Cambridge Univ. Press, 2014).

49. IPCC Climate Change 2014: Synthesis Report (Cambridge Univ. Press, 2014).

50. Mastrandrea, M. D. et al. The IPCC AR5 guidance note on consistent treatment of uncertainties: a common approach across the working groups. Climatic Change 108, 675-691 (2011).

51. Rogelj, J. et al. Energy system transformations for limiting end-of-century warming to below $1.5^{\circ} \mathrm{C}$. Nature Clim. Change 5, 519-527 (2015).

52. Statement of the CVF Chair at the UNFCCC COP21 Ministerial Dialogue on the Long-Term Goal (Climate Vulnerable Forum, 2015); http://go.nature.com/29DRiRy

53. Rogelj, J. et al. Zero emission targets as long-term global goals for climate protection. Environ. Res. Lett. 10, 105007 (2015).

54. IPCC Climate Change 2014: Mitigation of Climate Change (eds Edenhofer, O. et al.) (Cambridge Univ. Press, 2014) 
55. Rogelj, J. et al. Differences between carbon budget estimates unravelled. Nature Clim. Change 6, 245-252 (2016).

56. Meinshausen, M. et al. The RCP greenhouse gas concentrations and their extensions from 1765 to 2300. Climatic Change 109, 213-241 (2011).

57. Fuss, S. et al. Betting on negative emissions. Nature Clim. Change 4, 850-853 (2014).

58. Smith, P. et al. Biophysical and economic limits to negative $\mathrm{CO}_{2}$ emissions. Nature Clim. Change 6, 42-50 (2015).

59. Williamson, P. Scrutinize $\mathrm{CO}_{2}$ removal methods. Nature 530, 153-155 (2016).

60. Obersteiner, M. et al. Managing climate risk. Science 294, 786-787 (2001).

61. Kriegler, E. et al. The role of technology for achieving climate policy objectives: overview of the EMF 27 study on global technology and climate policy strategies. Climatic Change 123, 353-367 (2014).

62. Lobell, D. B. \& Tebaldi, C. Getting caught with our plants down: the risks of a global crop yield slowdown from climate trends in the next two decades. Environ. Res. Lett. 9, 074003 (2014).

63. Creutzig, F. et al. Bioenergy and climate change mitigation: an assessment. GCB Bioenergy 7, 916-944 (2014).

64. Smith, P. et al. in Climate Change 2014: Mitigation of Climate Change (Edenhofer, O. et al.) Ch. 11 (IPCC, Cambridge Univ Press, 2014)

65. Havlik, P. et al. Global land-use implications of first and second generation biofuel targets. Energy Pol. 39, 5690-5702 (2011).

66. Lotze-Campen, H. et al. Impacts of increased bioenergy demand on global food markets: an AgMIP economic model intercomparison. Agric. Econ. 45, 103-116 (2014)

67. Riahi, K. et al. Locked into Copenhagen Pledges - Implications of shortterm emission targets for the cost and feasibility of long-term climate goals. Technol. Forecast. Soc. Change 90A, 8-23 (2013).

68. The Emission Gap Report 2015: A UNEP Synthesis Report (UNEP, 2015)

69. Rogelj, J., McCollum, D. L., O’Neill, B. C. \& Riahi, K. 2020 emissions levels required to limit warming to below $2{ }^{\circ} \mathrm{C}$. Nature Clim. Change 3, 405-412 (2013).

70. Synthesis Report on the Aggregate Effect of the Intended Nationally Determined Contributions FCCC/CP/2015/7 (UNFCCC, 2015).

71. Rogelj, J. et al. Paris Agreement climate proposals need a boost to keep warming well below $2{ }^{\circ} \mathrm{C}$. Nature 534, 631-639 (2016).

72. Jaeger, C. C. \& Jaeger, J. Three views of two degrees. Reg. Environ. Chang. 11, 15-26 (2011)

73. Schellnhuber, H. J. Rahmstorf, S. \& Winkelmann, R. Why the right climate target was agreed in Paris. Nature Clim. Change 6, 649-653 (2016).

74. Rogelj, J. \& Knutti, R. Geosciences after Paris. Nature Geosci. 9, 187-189 (2016).

75. Mitchell, D. et al. Realizing the impacts of a $1.5^{\circ} \mathrm{C}$ warmer world. Nature Clim. Change 6, 735-737 (2016).

76. James, R. \& Washington, R. Changes in African temperature and precipitation associated with degrees of global warming. Climatic Change 117, 859-872 (2013)

77. Hallegatte, S. et al. Mapping the climate change challenge. Nature Clim. Change 6, 663-668 (2016)

78. Chadwick, R. \& Good, P. Understanding nonlinear tropical precipitation responses to $\mathrm{CO}_{2}$ forcing. Geophys. Res. Lett. 40, 4911-4915 (2013).

79. Hawkins, E., Joshi, M. \& Frame, D. Wetter then drier in some tropical areas. Nature Clim. Change 4, 646-647 (2014).

80. Bouttes, N., Gregory, J. M. \& Lowe, J. A. The reversibility of sea level rise. J. Clim. 26, 2502-2513 (2013).

81. Schleussner, C.-F., Levermann, A. \& Meinshausen, M. Probabilistic projections of the Atlantic overturning. Climatic Change 127, 579-586 (2014).

82. Drijfhout, S. et al. Catalogue of abrupt shifts in Intergovernmental Panel on Climate Change climate models. Proc. Natl Acad. Sci. USA 112, 43 (2015).

83. Joughin, I., Smith, B. E. \& Medley, B. Marine ice sheet collapse potentially underway for the Thwaites Glacier Basin, West Antarctica. Science 344, 735-738 (2014)

84. Rignot, E., Mouginot, J., Morlighem, M., Seroussi, H. \& Scheuchl, B. Widespread, rapid grounding line retreat of Pine Island, Thwaites, Smith and Kohler glaciers, West Antarctica from 1992 to 2011. Geophys. Res. Lett. 41, 3502-3509 (2014)

85. Favier, L. et al. Retreat of Pine Island Glacier controlled by marine ice-sheet instability. Nature Clim. Change 4, 117-121 (2014).
86. Feldmann, J. \& Levermann, A. Collapse of the West Antarctic Ice Sheet after local destabilization of the Amundsen Basin. Proc. Natl Acad. Sci. USA 112, 14191-14196 (2015)

87. Mengel, M. \& Levermann, A. Ice plug prevents irreversible discharge from East Antarctica. Nature Clim. Change 4, 451-455 (2014).

88. Spence, P. et al. Rapid subsurface warming and circulation changes of Antarctic coastal waters by poleward shifting winds. Geophys. Res. Lett. 41, 4601-4610 (2014)

89. Hellmer, H. H., Kauker, F., Timmermann, R., Determann, J. \& Rae, J. Twenty-first-century warming of a large Antarctic ice-shelf cavity by a redirected coastal current. Nature 485, 225-228 (2012).

90. Vuuren, D. P. et al. A new scenario framework for climate change research: scenario matrix architecture. Climatic Change 122, 373-386 (2014).

91. Steffen, W. et al. Planetary boundaries: guiding human development on a changing planet. Science 347, 1259855 (2015).

92. Lomax, G., Lenton, T. M., Adeosun, A. \& Workman, M. Investing in negative emissions. Nature Clim. Change 5, 498-500 (2015).

93. Meinshausen, M. et al. National post-2020 greenhouse gas targets and diversity-aware leadership. Nature Clim. Change 5, 1098-1106 (2015).

94. Edenhofer, O. King Coal and the queen of subsidies. Science 349, 1286-1287 (2015).

95. The Coal Gap: Planned Coal-Fired Power Plants Inconsistent with $2{ }^{\circ} \mathrm{C}$ and Threaten Achievement of INDCs (Climate Action Tracker, 2015).

96. Lelieveld, J., Evans, J. S., Fnais, M., Giannadaki, D. \& Pozzer, A. The contribution of outdoor air pollution sources to premature mortality on a global scale. Nature 525, 367-71 (2015).

97. Rogelj, J. et al. Air-pollution emission ranges consistent with the representative concentration pathways. Nature Clim. Change 4, 245-252 (2014).

98. Hulme, M. $1.5^{\circ} \mathrm{C}$ and climate research after the Paris Agreement. Nature Clim. Change 6, 222-224 (2016).

99. INDCs Lower Projected Warming to $2.7^{\circ} \mathrm{C}$ : Significant Progress But Still Above $2{ }^{\circ} \mathrm{C}$ (Climate Action Tracker, 2015)

\section{Acknowledgements}

We acknowledge the work by IAM modellers that contributed to the IPCC AR5 Scenario Database and the World Climate Research Programme's Working Group on Coupled Modelling, which is responsible for CMIP. We thank the climate modelling groups for producing and making available their model output, and the International Institute for Applied System Analysis for hosting the IPCC AR5 Scenario Database. For CMIP, the US Department of Energy's Program for Climate Model Diagnosis and Intercomparison provided coordinating support and led development of software infrastructure in partnership with the Global Organization for Earth System Science Portals. We would like to thank the modelling groups that participated in the InterSectoral Impact Model Intercomparison Project (ISI-MIP) and the Potsdam Institute for Climate Impact Research for hosting the database. The work was supported by the German Federal Ministry for the Environment, Nature Conservation and Nuclear Safety (11_II_093_Global_A_SIDS and LDCs), within the framework of the Leibniz Competition (SAW-2013-PIK-5), from EU FP7 project HELIX (grant no. FP7-603864-2) and by the German Federal Ministry of Education and Research (BMBF; grant no. 01LS1201A1). J.R. received funding from the EU's Horizon 2020 research and innovation programme under grant agreement no. 642147 (CD-LINKS)

\section{Author contributions}

C.F.S, J.R., M.S. and W.H. led the writing of the paper with significant contributions from all authors. C.F.S, J.R., M.S. and W.H. designed the manuscript structure and content C.F.S., J.R. and M.S. carried out the analysis presented and produced the figures.

\section{Additional information}

Supplementary information is available in the online version of the paper. Reprints and permissions information is available online at www.nature.com/reprints. Correspondence and requests for materials should be addressed to C.F.S.

\section{Competing financial interests}

The authors declare no competing financial interests. 